\title{
Smart Loan Generation System for Small and Medium Financial Enterprises
}

\author{
Pranjal Chikhaliker \\ Student, Computer Engineering \\ DYPIEMR, Pune
}

\author{
Suvarna Patil \\ Faculty, Computer Engineering \\ DYPIEMR, Pune
}

\author{
Shubham Jaiswal \\ Student, Computer Engineering \\ DYPIEMR, Pune
}

\author{
Dhanashree Patil \\ Student, Computer Engineering \\ DYPIEMR, Pune
}

\author{
Neeta Chavan \\ Student, Computer Engineering \\ DYPIEMR, Pune
}

\begin{abstract}
In the socio-economic development field, the Indian banking sectors play an important role through its pioneering as well as conventional services in the current period with innovative models in banking payments and small financing sectors. The paper focuses on the following question, "what factors would lead the customer to apply for a bank loan?". Four constituents namely human capital, business strategy, firm and information asymmetry underlie the theoretical framework of this study. The main purpose of the project is to develop a system model based on bank loan for its applicability.
\end{abstract}

\section{General Terms}

Loan Generation, Finance, SMEs

\section{Keywords}

Banking, Loan, Bank loan model, Socio economic development

\section{INTRODUCTION}

Evolution of banking sector, financial institutions and financial sector involved introduction and application of modern electronic and digital technologies which are based on using different types of computer systems, computing networks, digital communication along with usage of internet and mobile phones. Therefore, appropriate databases and software applications are required for fulfilling the different needs of the banking services. It increases speed, efficiency and security of all banking and financial operations and services. The banks and the clients of the bank services are highly benefited with this approach. All these proceedings lead to transformation of classical financial retail data banks into digital data banks. Therefore, to attain antiunity the system has been proposed to attain a similar graph for the banking sector for small and medium enterprises so as they could generate loan in any terms specifically gold loans, asset loans and vehicle loans so as the customer can apply for loan anytime and anywhere as pe the convenience.

The largest consumer of gold in the world is India. As per the census of World Gold Council (WGC), the annual gold demand in India has increased by 804\% from 1987 to 2016. The trend does not seem to decline easily. The precious metal which is used for commercial, industrial and investment purposes can also be used to get a loan at the time of a financial emergency. In fact, the fastest and easiest way to access funds during need is by generating gold loans.

The gold loan can be a prior solution if there is a low credit score but ample amounts of idle gold in the locker. With the growing popularity of gold loans each year, it is important to know how a gold loan works, what are their interest rates and other related details.

\section{OBJECTIVE}

Financing is one of the most trusted entities in the Small and Medium Banking \& Finance segment, and as part of its recent modernization drive, it is planned to digitize its product portfolio to reach a wide segment of peoples across India. At present these functional offerings are being carried out manually across the branches of the main cities.

Core Functional Offerings

- $\quad$ Gold / Silver Loan (Phase 1)

- Loan against Properties (Phase 2)

- Loan against Automobiles (Phase 3)

As part of phase 1, its planned to automate \& web enable the "Gold \& Silver Loan" application business.

\section{RELATED WORK}

The paper focuses on designing and development of fast and efficient informative service problems in order to solve the difficulty faced in the financing sector by the rural SMEs. This paper performs system requirement analysis elaborately, by repeated communication and exchange with bank and rural SMEs and also clarifies the functions to be identified by the system and completes designing of required modules in system as well as structural database design [1].

The System Advisor Model proposed by Nate Blair, Paul Gilman, Steve Jonzou which has the joint evaluation of host system and financial developer perspectives within the Advisory Model of the System contains several RE project financing which includes commercial loan partnership flips, residential mortgage and third-party ownership. However, a variety of users wanted to evaluate the system in which a third party owned the system, both from the developer's and system host perspective in a concurrent fashion. Therefore, a new developer and host co-model has been added and described. This model effectively succeeded in combining the previously-released "third party ownership" and "Single owner" models into the same analysis [2]. 
It is argued that networking is pivotal for small and mediumsized enterprises, particularly in emerging economies as to access resources for development. Bank financing is one key resource in emerging economies. The main focus is to examine the net effect of different network ties on finance banks to private SMEs through development of the model. The results support the hypothesis that different network ties influence SMEs use of bank loans in different ways. Specifically, use of bank loans is promoted if networking done with customers and government officials, while networking with suppliers and social ties would reduce the need for bank loans.[3]

To transform the classical banks into modern digital banks, the paper considers, proposes and describes possibilities and methods of using digital electronic technologies. Digital electronic technologies are widely used and included in banking operations and services being one of important sectors. Application of different types of digital technologies, which includes digital communication in communication technologies, computer networks, internet and information technologies with appropriate software would enable the increasing speed, security and efficiency of the banking operations and services. It provides ample amounts of benefits and advantages to the banks and to users of banking services. It is also a proposed organizational model of the digital bank.[4].

KYC based authentication system method for financial services proposed by Prakash Chandra Mondal, Rupam Deb, Md Nurul Huda gives a visionary idea how financial services are running through the internet which could be exposed to various threats such as pharming, phishing, malware and evolving sophistication due to compromise in techniques. To alleviate the risk and make it secure, a multi-factor authentication (MFA) financial service system can be used. Various methods of MFA run in troubles like false sense of security (if used on login devices), the authentication device lost or stolen, compromised answer of the generic question, unambiguous movement profile, higher implementation costs, calculated hash value stolen etc. Compliance with Know Your Customer (KYC), Anti-Money Laundering, and sanctioning requirements continue to be a key focus area for Financial Institutions' (FIs) management; firms must ensure that they meet the increasing regulatory demands in compliance with appropriate procedures. Analysis and simulation show that customers will get relief from holding additional security devices that incur huge costs [5].

\section{GOLD LOAN SYSTEM}

The loan against gold is also referred to as gold loan. It is a secured loan gateway between the borrower and the lender on behalf of the ornamental assets such as gold ornament. Based on the current percentage of the gold's value in the market, the loan amount would be sanctioned. The borrower is supposed to repay it through monthly installment. On successful repayment, the assets are returned back. There is no restriction on the end use of gold loans unlike other secured loans such as a home loan or car loan. Therefore, the essential urge to funding is properly fulfilled to meet the sudden money requirement. Moreover, organizations such as NBFCs offer gold loans at affordable interest rates along with corporate sectors and nationalized banks.

There is quite a similarity between the overall process of gold loan as well as other secured loans generation. Here, the gold assets are taken to the lender along with the required set of documents. The verification of submitted documents as well as evaluation of the gold assets are done carefully. As per the evaluations, the loan amount is sanctioned by the lender. In accordance with the loan agreement, the principal amount is paid along with the interest rate and the pledged gold articles back are returned back.

A person owning a gold can get a gold loan. With stringent eligibility criteria, any resident can avail the gold loan which includes all the sections of people from salaried professionals, businessmen, housewives, and even farmers. There is no need to have a good credit score to be eligible for a gold loan.

There is still enough chance to get funds through a low credit score as well, provided the client has enough gold to pledge for it.

Before sanctioning the gold application, the gold assessment and evaluation is done based on its purity and weight by the lender. The final amount to be disbursed is determined based on its current rate through the gold's market value. Most lenders offer a gold loan with a value up to 75 percent of the pledged gold's market value. For instance, if your gold is worth 1 lakh, the loan amount sanctioned to you would be not more than 0.75 lakhs. Besides the Loan to value ratio, loan amount also depends on various other factors such as tenure and the borrower's repayment capacity.

The process of repayment of a gold loan solely depends on the lender. Most of the identified lending institutions pay only the interest amount each month and the principal amount is paid at the end of the loan tenure. A person can also apply to pay through EMIs which includes both principal and interest component of the loan.

\section{SYSTEM ARCHITECTURE}

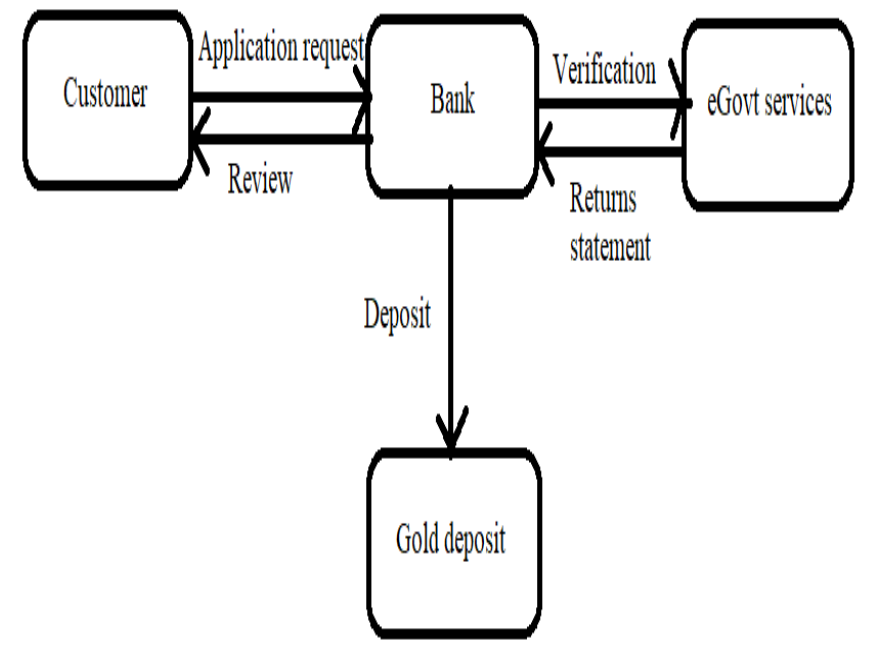

Fig 1: Architecture Diagram 


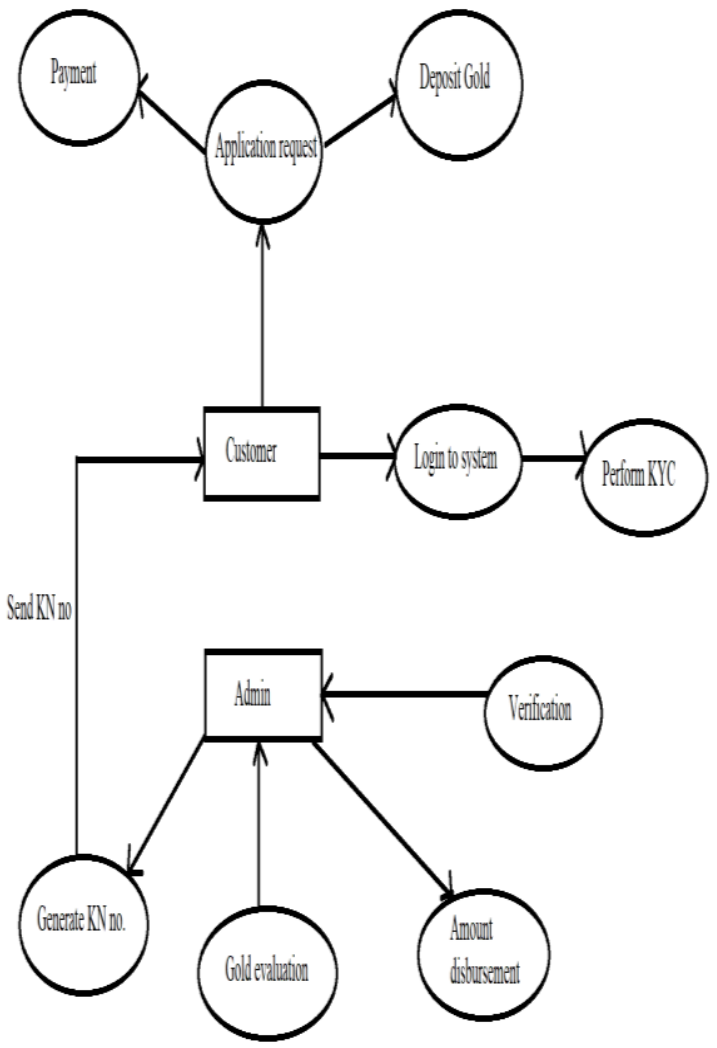

Fig 2: Workflow Diagram

\section{PROPOSED SYSTEM}

\subsection{Portfolio 1: Gold Loan}

This segment is the most revenue generation segment due to the volatility in the bullion markets. As part of this functionality, the financing customers of SMEs can deposit their Gold / Silver / Platinum ornaments and avail equivalent cash on a competitive market rate.

The following process is being carried out before taking the gold deposit from the end customer

\subsubsection{Customer KYC Verification}

Each customer has to submit their KYC Document to the bank, and get verified. Upon successful verification, the bank issues a unique KYC Security Number, called a KN. The Verification should not involve any manual interaction, and is able to do it with available APIs (such as connecting to eGovt Grid for validation docs like Aadhaar, Pan Card, Passport \& DL etc.).

\subsubsection{Gold Deposit Request}

KYC Completed Customer, will raise an Application request for Gold Loan, by entering following details
i. Customer Details
1. KN Number
ii. Asset Details
1. Gold Type- 8/16/24 Carat
2. Weight (in grams)
3. Place bought from
4. Jewelers Name and Address
5. Photo of the gold ornament

iii. Declaration iv.

Bank Details

1. Account holder name

2. Joint Account

3. Savings/Current

4. Account Number

5. IFSC Code

6. Bank Name

7. Branch Name

v. The above request would be captured in the system, and it triggers the workflow. The customer is given with the Request id (RID), for the proof for submission.

vi. The request will go through the following set of peoples (bank employees)

Step $1 \rightarrow$ All Details are verified and would get rejected for review in case if something found to be incorrect. Ex Incorrect Customer details, suspicious customer name pattern etc.

Step $2 \rightarrow$ The customer has to submit the gold to the nearest Finance office against the RID.

Step $3 \rightarrow$ Gold Evaluation by the Bank, and stores the Gold Quality Index against the RID

Step $4 \rightarrow$ Bank sends a notification to the Customer with the application status (accepted/rejected) etc. with amount it can disburse of the bullion deposited

Step $5 \rightarrow$ The customer can view, and opt either accept or reject the bank offer. In case of accept, the money is credited to the Customer Bank Account. In Case of reject, the customer can go back to the bank, and collect the Gold Ornaments after paying the required service fee (around $500 \mathrm{Rs}$ )

Step $6 \rightarrow$ Once the load is disbursed, this needs to be captured in the system.

\section{CONCLUSION}

The aim of this paper proves to be practically possible and efficient. Thus, improving the gold loan generation process in the socio-economic sector and making it simple and to innovate the banking models for small and medium enterprises for a smooth and consistent generation of the entire process through both employees side as well as the customers side and henceforth residing on the main purpose of the project of developing a bank loan model based on applicability.

\section{REFERENCES}

[1] Yu, S., 2017, May. Design and Implementation of Internet Financing Platform for Rural SMEs. In 2017 International Conference on Smart Grid and Electrical Automation (ICSGEA) (pp. 668-671). IEEE.

[2] Chirag Rathod, ChiragRanpura, Chirag Patel, 2016. Star Small and Medium Banking and Finance, pp.210-216.

[3] Le, N.T. and Nguyen, T.V., 2009. The impact of networking on bank financing: The case of small and medium-sized enterprises in Vietnam. Entrepreneurship theory and practice, 33(4), pp.867-887

[4] Klapper, L., 2005. The role of factoring for financing small and medium enterprises. The World Bank. 
[5] Abe, M., Troilo, M. and Batsaikhan, O., 2015. Financing small and medium enterprises in Asia and the Pacific. Journal of Entrepreneurship and Public Policy.

[6] Sajić, M., Bundalo, D., Bundalo, Z. and Pašalić, D., 2017, November. Digital technologies in transformation of classical retail bank into digital bank. In 2017 25th Telecommunication Forum (TELFOR) (pp. 1-4). IEEE. Brown, L. D., Hua, H., and Gao, C. 2003.

[7] Lee, M.C., 2009. Factors influencing the adoption of internet banking: An integration of TAM and TPB with perceived risk and perceived benefit. Electronic commerce research and applications, 8(3), pp.130-141.

[8] Maina, E.W., 2014. Small and Medium Sized Enterprises Access To Finance as A Growth Constraint Case Study: Chase Bank's Asset Financing

[9] Mondal, P.C., Deb, R. and Huda, M.N., 2016, December. Know your customer (KYC) based authentication method for financial services through the internet. In 2016 19th International Conference on Computer and Information Technology (ICCIT) (pp. 535-540). IEEE.

[10] Council, F.F.I.E., 2005. Authentication in an internet banking environment. FFIEC agencies (August 2001 Guidance).

[11] Aithal, P.S., 2016. A review on advanced security solutions in online banking models. International Journal of Scientific Research and Modern Education (IJSRME), 1, pp.421-429.

[12] Hsieh, W.B. and Leu, J.S., 2011, July. Design of a time and location based One-Time Password authentication scheme. In 2011 7th international wireless communications and mobile computing conference (pp. 201-206). IEEE. 